\title{
ANALISIS MINAT MASYARAKAT MENABUNG EMAS PADA UNIT PEGADAIAN SYARIAH SELAYO SOLOK
}

\author{
1Muhammad Deni Putra, ${ }^{2}$ Gusti Rahayu Ningsih, ${ }^{3}$ Frida Amelia \\ Corresponding author's : Fakultas Ekonomi dan Bisnis Islam, IAIN Batusangkar \\ e-mail: mdeniputra@iainbatusangkar.ac.id
}

Copyright (C) 2021

\begin{abstract}
This research was motivated because there was a lack of public interest in saving gold at Sharia Pawnshop Unit in Selayo Solok. The research was done to know the reasons of lack of public interest in saving gold at Sharia Pawnshop Unit in Selayo Solok. The design was a field research. The data was collected through observation, interview, and dokumentation. The data was analyzed through descrptive qualitative approach. The result showed indicated that the public had lack of interest in saving gold at Sharia Pawnshop Unit in Selayo Solok. It was caused by lack of outreach to the public, inadequate economy, distant public sttlements, and the absence of a savings pick-up system eventough this unit had already done some efforts such as giving discouts and souvenirs, can save money in short or long time, can be printed in the form of money or gold bar, and low administrative costs.
\end{abstract}

Keywords: minat masyarakat, menabung emas, pegadaian syariah

\section{PENDAHULUAN}

Istilah Pegadaian saat ini tidak lagi menjadi istilah asing di tengah-tengah masyarakat. Dibandingkan dengan lembaga keuangan lainnya Pegadaian dipandang sebagai lembaga keuangan yang memberi kemudahan bagi masyarakat. Sesuai dengan mottonya yaitu mengatasi masalah tanpa masalah telah membuat pegadaian menjadi alternatif untuk memperoleh uang tunai dengan segera. Satu-satunya kegiatan gadai yang sudah berkembang di Indonesia adalah perum Pegadaian (Iska dan Nengsih, 2016: 100).
Pegadaian syariah hadir dengan berbagai layanan dengan mempermudah nasabah dalam berinvestasi jangka panjang, atau mendapatkan pembiayaan sesuai dengan kebutuhan usaha. Produk-produk pegadaian syariah diantaranya: Rahn yaitu solusi untuk memiliki dana cepat sesuai syariah, rahn di pegadaian terbagi dua yaitu rahn dan rahn hasan, Amanah (pembiayaan diberikan kepada usaha mikro atau UKM untuk memiliki motor atau mobil dengan cara angsuran, Multi Pembayaran Online (melayani pembayaran berbagai tagihan seperti listrik dan telfon atau pulsa-pulsa). Kemudian pegadaian memiliki produk Arrum, 
produk Arrum terbagi tiga Arrum BPKB, Arrum Haji, Arrum Emas. Kemudian pegadaian memiliki produk investasi yaitu produk Mulia dan produk Tabungan Emas. (www.pegadaiansyariah.com 2018 Februari 23).

Berdasarkan data yang diperoleh, pada tahun 2016 nasabah yang membuka tabungan emas di pegadaian syariah sebanyak 116 orang, pada tahun 2017 jumlah nasabah yang membuka tabungan emas di pegadaian mengalami penurunan menjadi 85 orang, dan pada tahun 2018 jumlah nasabah yang membuka tabungan emas di pegadaian mengalami kenaikan menjadi 195 orang. Dari data diatas dapat dilihat bahwa nasabah Tabungan Emas Unit Pegadaian Syariah Selayo Solok tahun 2016-2018 mengalami fluktuasi.

Sementara itu kalau diamati dari situs resmi pegadaian, dapat dilihat bahwa produk tabungan emas memiliki banyak keunggulan, di antaranya produk tabungan emas memberikan peluang kepada nasabah untuk melakukan investasi jangka panjang, serta produk tabungan emas tidak ditetapkan seberapa besar nasabah ingin menyetor dan nasabah juga tidak dikenakan denda. Melihat peluang yang ada, semestinya jumlah nasabah tabungan emas terus meningkat, tapi prakreknya pada tahun 2017 jumlah nasabah Unit Pegadaian Syariah Selayo Solok mengalami penurunan sekitar $40 \%$.

Berdasarkan wawancara dengan Eka Isra Wahyuli selaku pngelola pada
Pada Unit Pegadaian Syariah Selayo Solok, tabungan emas memiliki target peningkatan jumlah nasabah setiap tahunnya, target peningkatan sejumlah 850 nasabah tabungan emas. Target ini seharusnya dapat tercapai oleh Unit Pegadaian Syriah Selayo Solok karena dilihat dari potensi jumlah penduduk Kabupaten solok. Berikut tabel Jumlah Penduduk Kabupaten Solok.

Tabel 1. 1

Jumlah Penduduk Kabupaten Solok per Tahun

\begin{tabular}{|c|c|c|}
\hline Nomor & Tahun & $\begin{array}{c}\text { Jumlah } \\
\text { Penduduk }\end{array}$ \\
\hline 1 & 2016 & 366.213 jiwa \\
\hline 2 & 2017 & 368.692 jiwa \\
\hline 3 & 2018 & 368.692 jiwa \\
\hline
\end{tabular}

Sumber: BPS Kabupaten Solok

Dilihat dari data yang diperoleh Unit Pegadaian Syariah memiliki banyak produk salah satunya produk tabungan emas. Produk tabungan emas memiliki jumlah nasabah paling tinggi dibandingkan produk investasi mulia, namun tingginya jumlah nasabah tabungan emas tersebut masih belum mencapai jumlah nasabah yang ditargetkan oleh Kantor Pusat Pegadaian, sedangkan untuk Tabungan emas di Unit pegadaian syariah dapat mencapai target tersebut dilihat dari jumlah penduduk pada Kabupaten Solok yang mencapai 368.692 jiwa. Melihat potensi yang ada kurangnya pencapaian target tabungan emas pegadaian, apakah disebabkan oleh kurangnya pengetahuan dari masyarakat Kabupaten Solok terhadap investasi menabung emas Pegadaian syariah? Atau dikarenakan 
kurangnya sosialisasi dari Pegadaian itu sendiri?

\section{KAJIAN TEORI}

\section{Pengertian Minat}

Minat adalah suatu dorongan yang menyebabkan terikatnya perhatian individu pada objek tertentu seperti pekerjaan, pelajaran, benda dan orang. Minat berhubungan dengan aspek kognitif, efektif, dan motorik dan merupakan sumber motivasi untuk melakukan apa yang diinginkan (Jahja, 2011: 63).

\section{Faktor-Faktor yang Mempengaruhi Minat Masyarakat Menabung}

Pengetahuan, pelayanan dan lokasi merupakan faktor yang penting dalam usaha menarik minat konsumen atau pelanggan. Faktor-faktor yang mempengaruhi kurangnya minat masyarakat menabung yaitu:

1) Pengaruh pengetahuan terhadap minat menabung.

Pengetahuan merupakan hasil dari tahu dan ini terjadi setelah orang melakukan pengindraan terhadap suatu objek tertentu. Pengindraan terjadi melalui pancaindra manusia, yakni indra penglihatan, pendengaran, penciuman, rasa dan raba dengan sendiri. Sebagian besar pengetahuan manusia diperoleh melalui mata dan telinga.

2) Pengaruh pelayanan terhadap minat menabung

Istilah pelayanan dapat dipersepsikan berbeda-beda dalam konteks yang berlainan. Pelayanan adalah setiap tindakan atau kegiatan yang dapat ditawarkan oleh suatu pihak kepada pihak lain, yang pada dasarnya tidak berwujud dan tidak mengakibatkan kepemilikan apapun. Pelayanan merupakan prilaku produsen dalam rangka memenuhi kebutuhan dan keinginan konsumen demi tercapainya kepuasan pada konsumen itu sendiri. Kotler juga mengatakan bahwa prilaku tersebut dapat terjadi pada saat sebelum dan sesudah terjadinya transaksi.

Ada beberapa aspek yang perlu diperhatikan oleh perusahaan yang mampu mengarahkan operasional perusahaan pada aktifitas pelayanan jasa yang baik. Di antaranya yang paling penting adalah akses. Akses ini berhubungan dengan letak perusahaan yang strategis, pasar, sasaran, serta kemampuan yang mampu memberikan pelayanan yang cepat.

3) Pengaruh lokasi terhadap minat menabung

Lokasi adalah letak atau toko pengecer pada daerah yang strategis sehingga dapat memaksimumkan laba. Pertimbangan dalam memilih letak lokasi yaitu berdasarkan jenis usaha yang akan dilakukan, keterdekatan dengan pasar atau konsumen, kemudahan sarana dan prasarana, kemudian untuk melakukan ekspansi dekat dengan pusat pemerintahan, dan tersedianya sumber daya yang lain (Irnawati, 2019, 10-11). 


\section{Tabungan Emas}

Tabungan emas adalah layanan pembelian dan penjualan emas dengan fasilitas titipan dengan harga yang terjangkau. Layanan ini memberikan kemudahan kepada masyarakat untuk berinvestasi emas. Bagi yang tidak memiliki dana untuk menaruh membeli emas, kini bisa mengikuti program menabung emas di Pegadaian. Pegadaian selaku Badan Usaha Milik Negara (BUMN) membuat produk untuk mencari orang-orang yang ingin menabung emas. Produk ini dinamakan tabungan emas, layanan ini memberikan kemudahan kepada masyarakat untuk mulai berinvestasi emas (pegadaian.co.id/produk/tabunganemas.php 2018 Januari 16).

\section{Pengertian Pegadaian}

Pegadaian adalah salah satu bentuk lembaga keuangan bukan bank yang diperuntukkan bagi masyarakat luas berpenghasilan menengah ke bawah yang membutuhkan dana dalam waktu segera. Dana ini digunkan untuk membiayai kebutuhan tertentu terutama yang sangat mendesak (Mardani, 2015: 171).

Gadai adalah suatu hak yang diperoleh seseorang yang berpiutang atas suatu barang bergerak yang diserahkan kepadanya oleh seseorang yang berhutang atau oleh seseorang lain atas namanya dan yang memberikan kekuasaan kepada sipemilik piutang untuk mengambil pelunasan dari hutangnya melalui barang tersebut apabila yang berhutang tidak mampu membayar hutangnya setelah dikurangi semua biaya-biaya yang terjadi akibat hutang piutang tersebut (Iska dan Nengsih, 2016: 101).

Gadai menurut Undang-undang Hukum perdata (Burgenlijk Wetboek) Buku II Bab XX pasal 1150, adalah suatu hak yang diperoleh seorang yang berpiutang atas suatu barang bergerak, yang diserahkan kepadanya oleh seseorang berutang atau atas seorang yang lain atas namanya, dan yang memberikan kekuasaan kepada yang berpiutang itu untuk mengambil pelunasan dari barang tersebut secara didahulukan dari pada orang-orang berpiutang lainnya, dengan pengecualiaan biaya untuk melelang barang tersebut dan biaya yang telah dikeluarkan untuk menyelamatkannya setelah barang itu digadaikan, biayabiaya mana yang harus dikeluarkan.

Dalam fiqih uslam istilah pegadaian disebut ar-rahn. Secara etimologis ar-rahn berarti tsubut (tetap) dan dawam (kekal, terus-menerus). Adapun secara terminologis, ar-rahn adalah menjadikan harta benda sebagai jaminan utang agar utangnya itu dilunasi (dikembalikan) atau di bayarkan harganya jika tidak dapat mengembalikannya. Dalam pengertian lain, ar-rahn adalah suatu jenis perjanjian untuk menahan suatu barang sebagai tanggungan utang (Mardani, 2015: 171). 


\section{METODE PENELTIAN}

\section{Desain Penelitian}

Jenis penelitian yang digunakan adalah field research (penelitian lapangan) dengan metode deskriptif kualitatif yaitu untuk menjelaskan dan menggambarkan tentang minat masyarakat menabung emas pada Unit Pegadaian Syariah Selayo Solok. Creswell mengatakan bahwa penelitian kualitatif adalah proses eksplorasi dan memahami makna prilaku individu dan kelompok (Sugiyono, 2014: 348).

\section{Obyek dan Waktu Penelitian}

Penelitian ini dilakukan di PT. Pegadaian (Persero) Unit Syariah Selayo yang beramalat di Jln. Raya Padang-Solok simpang By Pass Selayo, Sumatera Barat. Sedangkan waktu penelitian diakukan terhitung dari bulan Maret 2019 sampai dengan bulan Januari 2020.

\section{Instrumen Penelitian}

Instrument penelitian kualitatif adalah "human instrument" atau manusia sebagai informan maupun yang mencari data. Instrument dalam penelitian ini adalah peneliti sendiri sebagai ujung tombak pengumpul data (instrument). Peneliti terjun secara langsung kelapangan untuk mengumpulkan sejumlah informasi yang dibutuhkan dengan terlebih dahulu sudah memiliki beberapapedoman yang akan dijadikan alat bantu mengumpulkan data (Djam'an Satori dan Aan Komariah, 2012: 90). Dalam pelaksanaannya menggunakan alat bantu berupa pedoman wawancara. Instrumen pendukung lainnya yang berguna untuk menunjang kelengkapan data adalah, handphone, camera, dan note book

\section{HASIL PENELTIAN DAN PEMBAHASAN}

Minat Masyarakat Menabung Emas Pada Unit Pegadaian Syariah Selayo Solok

Hasil temuan penelitian yang telah penulis paparkan diatas, kurangnya minat masyarakat menabung emas pada Unit Pegadaian Syariah Selayo Solok disebabkan oleh beberapa faktor diantaranya:

1. Belum maksimalnya proses sosialisasi yang dilakukan oleh Pegadaian Syariah Selayo Solok.

Sosialisasi yang dilakukan oleh Pegadaian Syariah Selayo Solok hanya dilakukan ke kantor dinas dan instansiinstansi yang ada di kabupaten solok, hal ini karena kurangya tenaga marketing pada lembaga pegadaian syariah yang mana pegadaian tidak memiliki marketing untuk dapat bersosialisasi ke masyarakat-masyarakat secara langsung mengenai produkproduk yang ada di pegadaian, sehingga sebagian besar masyarakat kabupaten solok tidak mengetahui tentang pegadaian syariah dan produdk-produk yang ada. Mereka hanya mengetahui pegadaian biasa dan pegadaian hanya tempat menggadai saja. 


\section{Lokasi yang kurang strategis}

Kurangnya minat masyarakat dalam bertransaksi menabung emas pada Unit Pegadaian syariah selayo Solok dikarenakan oleh letak pemukiman masyarakat yang jauh dari kantor pegadaian sehingga tidak memungkinkan masyarakat untuk pergi menabung, dan pegadaian tidak memiliki layanan antar jemput tabungan sehingga menyulitkan bagi masyarakat untuk bertransaksi. Sebaiknya pegadaian memiliki sistem layanan antar jemput tabungan yang dapat memberi kemudahan bagi masyarakat yang tempat tinggalnya berjauhan dari kantor pegadaian.

Teori Kotler mengatakan bahwa ada beberapa aspek yang perlu diperhatikan oleh perusahaan yang mampu mengarahkan operasional perusahaan pada aktivitas layanan jasa yang baik. Diantara yang paling penting adalah akses. Akses ini berhubungan dengan letak perusahaan yang strategis, pasar, sasaran, serta kemampuan yang mampu memberikan pelayanan yang tepat.

\section{Pengaruh ekonomi masyarakat terhadap minat menabung}

Sebagian kecil kurangnya minat masyarakat dalam bertransaksi menabung emas pada Unit Pegadaian Syariah Selayo Solok disebabkan karena faktor ekonomi yang mana ekonomi masyarakat yang belum memadai untuk berinvestasi karena masih ada keperluan lain yang harus dipenihi.
Upaya Pegadaian untuk Meningkatkan Jumlah Nasabah Tabungan Emas Pegadaian Syariah Selayo Solok

Hasil dan pembahasan analisi pada Berdasarkan teori faktor-faktor yang menjkadi minat nasabah salah satunya yaitu marketing mix yang mana para pemasar menggunkan sejumlah alat mendapatkan yang diinginkan dari pasar sasaran mereka, alat-alat itu membentuk beberapa bauran pemasaran (Andespa, 2017: 45).

Upaya yang dilakukan Unit Pegadaian Syariah Selayo Solok dalam menarik minat Masyarakat yaitu melakukan sosialisasi ke kantor-kantor dinas yang ada di kabupaten Solok dengan memberikan potongan harga atau menggratiskan biaya adminstrasi kepada calon nasabah untuk membuka Tabungan Emas, dan juga memberikan souvenir salah satunya berupa celengan pada acaraacara tertentu seperti acara seminar dan sponsorship.

Sosialisasi yang dilakukan ke kantor-kantor dinas dilakukan oleh tim pemasaran, yang mana tim pemasaran tidak selalu aktif untuk Unit Pegadaian Syariah Selayo Solok, karena tim pemasaran memegang beberapa wilayah di Sumatra barat untuk membantu pertumbuhan kantor unit dan cabang pegadaian. Seharusnya pegadaian syariah selayo solok memiliki tenaga marketing yang bekerja khusus untuk Unit Pegadaian Syariah Selayo Solok, agar marketing tersebut dapat datang langsung ke masyarakat setiap harinya untuk 
mencari nasabah dengan bersosialisasi, maka dari itu masyarakat akan dapat mengetahui apa itu Pegadaian Syariah dan produk-produk yang ada di Pegadaian Syariah hari ini.

\section{PENUTUP}

Berdasarkan hasil penelitian, maka disimpulkan sebagai berikut:

1. Dari penelitian yang penulis lakukan, maka dapat diambil kesimpulan bahwa minat masyarakat kabupaten Solok dalam menabung emas pada Unit Pegadaian Syariah Selayo Solok masih rendah. Secara umum alasan minimnya masyarakat menabung yaitu kerena kurangnya pengetahuan tentang produk Tabungan Emas Pegadaian Syariah, kurangnya sosialisasi dari Pegadaian Syariah ke masyarakat-masyarakat, ekonomi yang belum memadai, letak pemukiman masyarakat yang jauh sehingga sulit untuk pergi menabung ke Pegadaian Syariah Selayo Solok, tidak adanya sistem antar jemput tabungan di Pegadaian Syariah Selayo Solok.

2. Upaya Pegadaian dalam meningkatkan minat nasabah Tabungan Emas melalui sosialisasi dengan memberikan potongan harga, melalui seminar, dan sponsorship.

3. Keunggulan dan kelemahan dari Tabungan Emas Pegadaian Syariah adalah menabung mulai dari jumlah yang rendah sampai jumlah yang tidak ditentukan, dapat dicairkan dalam bentuk saldo uang dan dicetak dalam bentuk emas batangan, biaya administrasi yang murah, ditujukan untuk semua jenis kalangan masyarakat, sebagai investasi jangka panjang. Sedangkan kelemahan pegadaian tidak mempunyai tim marketing, tidak mempumyai sistim antar jemput tabungan sehingga bagi masyarakat yang akses jauh dari kantor merasa sulit untuk pergi bertransasksi, kelemahan dari sisi produk tabungan emas sendiri yaitu adalah harga emas yang tidak stabil tidak menguntungkan apabila dicairkan dalam jangka pendek, apabila dicairkan dalam bentuk emas batangan dikenakan biaya cetak.

\section{DAFTAR KEPUSTAKAAN}

Andespa, R. 2017. Faktor-Faktor yang Mempengaruhi Minat Nasabah dalam Menabung di Bank Syariah. Jurnal Lembaga Keuangan dan Perbankan 2(1) ISSN: 43-57

Irnawati. 2019. Faktor-Faktor yang Mempengaruhi Minat Masyarakat Menabung di Bank Syariah. Jurnal Lembaga Keuangan Syariah 2(1) ISSN: 10-11

Iska, S. Dan I. Nengsih. 2016. Manajemen

Lembaga Keuangan Syariah Non Bank Teori, Praktek Dan Regulasi. Padang: CV Jasa Surya

Jahja, Y. 2011. Psikologi Perkembangan. Jakarta: Kencana

Mardani. 2015. Aspek Hukum Lembaga Keuangan Syariah Di Indonesia. Ja karta: Kencana 
Rahmawati, T. 2017. Pengaruh Produk Peagadaian Syariah (Tabungan Emas) Terhadap Peningkatan Kesejahteraan Masyarakat. Skripsi Jurusan Ekonomi Syariah Fakultas Ekonomi dan Bisnis Islam Sekolah Tinggi Agama Islam Pelita Bangsa. Bekasi

Satori, Djam'an. 2012. Metodologi Penelitian Kualitatif. Bandung: Alfabeta
Sugiyono. 2014. Metode Penelitian Kuan titatif, Kualitatif Dan R\&D. Bandun g: Alfabeta

www.pegadain.co.id

www.pegadaiansyariah.com 